\title{
NOTAS
}

\section{Profesor Osvaldo Rodríguez Pérez (1944-2015)}

El dos de febrero de dos mil quince, falleció en Las Palmas de Gran Canaria el destacado académico Osvaldo Rodríguez Pérez, quien fuera profesor de la Universidad Austral de Chile entre los años 1973 y 1981. Para quienes le conocimos en la Facultad de Filosofía y Humanidades de esta casa de estudios, Osvaldo dejó una huella imborrable a través de un quehacer siempre comprometido y trascendente. A su pasión por la literatura española e hispanoamericana, añadía características personales muy entrañables: amable, sencillo, estudioso, comprometido con su labor docente, en todo momento se distinguió por ser un investigador $\mathrm{y}$ emprendedor infatigable de proyectos académicos y educacionales. Pero, por sobre todas las cosas, fue un gran amigo,

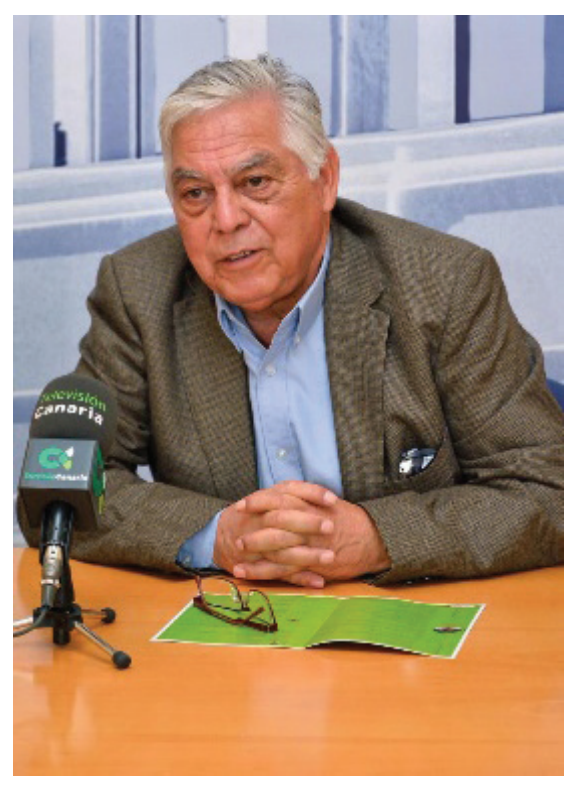
en quien destacaba un excelente sentido del humor, y una verdadera fascinación por la lectura, las mujeres y el vino (nunca pude descubrir cuál era el orden). Es justo también señalar el amor que siempre manifestó por su familia, especialmente, por sus hijos e hijas, así como por el país que lo vio nacer y su amada Valdivia, y por la España que lo adoptó y reconoció como un gran catedrático de literatura, tanto en el Madrid en que estudió, como en el archipiélago Canario, donde trabajó desde 1986 hasta su muerte.

En la Universidad Austral de Chile ingresó a estudiar Castellano en 1968, titulándose en 1972, y, posteriormente, pasó a estudiar Filosofía. Al año siguiente, en 1973, se incorporó como docente en el Área de Literatura. Fue Director del Instituto de Literatura Universal e Iberoamericana, y una de sus grandes obras fue la gestión que permitió instaurar el primer Programa de Posgrado de la Universidad Austral: el señero Magíster en Literatura, que significó un extraordinario impulso para el desarrollo académico de un importante número de profesores de las principales universidades del sur de Chile. En 1981 decidió abandonar el país, en un acto tan voluntarioso como heroico. Prácticamente sin ayuda económica que sustentara sus sueños y anhelos de perfeccionamiento, se matriculó en el doctorado en Literatura 
Hispanoamericana de la Universidad Complutense de Madrid, en donde se graduó con honores en 1985. Al año siguiente comenzó a trabajar en la Universidad de Las Palmas de Gran Canaria (en aquel entonces Universidad de La Laguna). Allí, junto con una destacada carrera académica, logró la ansiada Cátedra en Literatura, convirtiéndose en uno de los primeros catedráticos en su área en la naciente casa de estudios. Además de sus clases e investigaciones, de sus innumerables artículos y publicaciones, estuvo a cargo del Doctorado en Literatura, y de la Cátedra "Mario Vargas Llosa", Premio Nobel con quien compartía una gran amistad.

Si mientras estuvo en Chile su pasión se volcó en Cervantes, cuando estuvo en España sus ojos y esfuerzos se centraron en Neruda. Y este vaivén no fue casual. Cuando trabajaba en Chile, durante la cruenta dictadura militar que agobiaba el ambiente universitario, la esperanza le hacía poner los ojos en la lejana y cercana España. Lejana, geográficamente, y cercana, porque en su corazón blandía el espíritu quijotesco de su personaje más amado. Desde España, la angustia por apartarse de sus círculos más cercanos se consolaba con la poesía universal de Neruda que le evocaba el entorno bucólico del sur de Chile, al cual tenía la esperanza de volver para instalarse en un campo a criar ganado. Y es que la angustia y la esperanza marcaron la vida de nuestro apreciado profesor y amigo. Angustia por la precariedad económica en sus tiempos de estudiante; esperanza en que sus esfuerzos y talento estudiantil le depararían otro destino. Angustia de vivir en una universidad vigilada; esperanza de desarrollar su espíritu libre en un ambiente universitario liberado. Angustia por la distancia que le separaba de sus seres queridos; esperanza de volver a estar con ellos para siempre. Esta dualidad tan disyuntiva, lejos de transformarlo en un ser hosco u hostil, le enriqueció de tal manera que todos disfrutábamos de su compañía y atenta preocupación hacia sus coterráneos, de su experiencia, de su conversación, de su alegría y espíritu solidario, demostrado en su permanente disposición a servir y ayudar, especialmente a los estudiantes y, de entre ellos, a los más necesitados.

En uno de sus últimos y más logrados trabajos, "La poesía póstuma de Pablo Neruda: Viaje al interior de sí mismo", incluía el siguiente epígrafe del escritor: "Si nada nos salva de la muerte, al menos que el amor nos salve de la vida”. Tal cual lo conversáramos tantas veces, en Valdivia, en Sardina del Mar, o en Las Palmas: de la muerte sólo revivirán los recuerdos de quien te quiere y mantiene en vida mientras tu imagen permanezca en la memoria. Y la imagen tuya, querido profesor y amigo, permanecerá -imperecedera- en quienes te admiramos y quisimos durante más de cuarenta años de fecunda amistad y cariño.

Dr. Marcos Urra Salazar

Profesor del Instituto de Lingüística y Literatura

Universidad Austral de Chile 